\title{
QUESTÕES DE GÊNERO NO MUNDO RURAL E NA EXTENSÃO RURAL BRASILEIRA
}

\author{
Ana Paula Schervinski Villwock ${ }^{1}$ \\ Alessandra Regina Muller Germani ${ }^{2}$ \\ Patrícia Eveline dos Santos Roncato ${ }^{3}$
}

\begin{abstract}
Resumo
Os movimentos feministas têm avançado na busca pela garantia de direitos iguais aos do homem. As características biológicas de homens e mulheres são herdadas, enquanto as diferenças de gênero são construídas socialmente e por isso podem variar no tempo e no espaço e são sujeitas às mudanças. Assim, considerando o meio rural observa-se que o trabalho realizado pela mulher agricultora não é visto, e tão pouco reconhecido como um trabalho, sofrendo diferentes preconceitos e se estende para as atividades de extensão rural no Brasil. Nesse sentido, este estudo analisou algumas conexões entre o movimento feminista e a construção da categoria gênero, dando ênfase ao meio rural e a extensão rural brasileira. Dessa forma, esse estudo permitiu abordar que o feminismo está longe de ser um consenso na sociedade como um todo, inclusive na brasileira. Além disso, quando se discute as questões de gênero no meio rural e na extensão rural nota-se que essas relações estão ainda menos presentes nesse contexto. As perspectivas são de que sejam revistas as políticas públicas, mesmo existindo ainda um conflito entre as mulheres rurais e o mundo rural contemporâneo, necessitando de um avanço nas discussões da extensão rural e do desenvolvimento rural do país.
\end{abstract}

Palavras-chaves: Feminismo, gênero, meio rural.

\begin{abstract}
Feminist movements have advanced in the quest for ensuring equal rights of man. However, the biological characteristics of men and women are inherited, while gender differences are socially constructed and therefore may vary in time and space and are subject to change. Considering in rural areas it is observed that the work done by women farmers is not seen, and so little recognized as a job, experiencing different prejudices and this situation extends to the extension of activities in Brazil. Thus, this study analyzed some connections between the feminist movement and the construction of gender category, with an emphasis on rural areas and Brazilian extension. Thus, this study allowed to approach about feminism that is far from a consensus in society as a whole, including in Brazil. The prospects are that magazines are public policies, even though there are still a conflict among rural women and the contemporary rural world, needing a breakthrough in the discussions of the agricultural extension and rural development.
\end{abstract}

Key-words: Feminism, Gender, Countryside.

\footnotetext{
${ }^{1}$ Pesquisador sobre desenvolvimento rural e agricultura familiar - UFSM

${ }^{2}$ Pesquisador sobre desenvolvimento rural e saúde - UFSM

${ }^{3}$ Pesquisador sobre desenvolvimento rural e economia - UNIPAMPA
} 


\section{INTRODUÇÃO}

As reflexões sobre o feminismo têm aumentado significativamente nas últimas décadas, e como ideologia é uma das que apresentam um dos desenvolvimentos mais rápidos. Mas, deve-se ter claro que feminismo tem a ver com liberdade e que os papéis de gênero são construções sociais e não verdades naturais e universais. Nenhum papel de gênero deve limitar as pessoas, homens ou mulheres, ou ainda permitir que um sexo sofra violência, seja mais discriminado, tenha menos direitos e seja considerado de forma desigual.

Entende-se que afora da descrição do feminismo em termos gerais, é bastante difícil propor uma definição mais substantiva, sendo que algumas feministas até questionam a busca por uma definição. Tendo em vista que o feminismo, conforme Vincent (1995) encontra-se ainda em estágio de formação intelectual e política, se compararmos com outras ideologias como o liberalismo, é possível verificar a presença de intensas controvérsias, pois se trata de uma ideologia e de um movimento profundamente orientado pela ação/prática. Essa crítica ativo/prática, ou imanente, proposta pelo feminismo é quase exclusiva, visto que sua contestação não se dá apenas pelo plano acadêmico ou político, mas também é dirigida à crenças profundamente enraizadas no caráter da sociedade, em nossos padrões de pensamento e em nossas relações pessoais mais íntimas.

Além das diferentes definições de feminismo, há diferentes ideias que segundo Vincent (1995) que tem se investigado ao longo da história do feminismo como um movimento, que vão de associações à promoção da castidade quanto à inauguração das relações sexuais livres com apoio de anticoncepcionais gratuitamente disponíveis. Essas diversas doutrinas não surpreendem, visto que o feminismo partilha, em seus valores substantivos, a mesma superposição e ambivalência da maioria das ideologias. O mesmo autor ainda corrobora dizendo que essa ambiguidade reflete-se nas tentativas de definição de alguns autores, sendo que a noção mais geral do que seria feminismo é busca por "qualquer grupo que tenha tentado mudar a posição das mulheres ou as ideias acerca destas".

Dessa forma, tendo como base o conceito de gênero como referência para a análise reflexiva, procura-se chamar a atenção para a construção social e histórica do feminino e do masculino e para as relações sociais, marcadas em nossa sociedade por uma forte assimetria. É valido ressaltar que Brumer e Paulilo (2004) afirmam que enquanto a categoria 'sexo' diz respeito a categorias biológicas associadas ao homem e à mulher, a noção de gênero abrange a 
ideia de que a sociedade, por razões culturais, sociais, econômicas e políticas, atribui diferentes papéis a ambos os sexos.

Assim, as características biológicas de homens e mulheres são herdadas, enquanto as diferenças de gênero são construídas socialmente; portanto, podem variar no tempo e no espaço e são sujeitas a mudanças. E é somente através do reconhecimento dessas diferenças e da luta para mudar o quinhão das mulheres que se podem tornar as relações de gênero mais equitativas.

Sendo assim, ressalta-se que as mulheres estão de alguma forma presentes em diversas atividades de desenvolvimento dos países intimamente ligadas aos costumes, tradições e valores. Neste contexto, é que emerge uma série de debates sobre as desigualdades sociais presentes neste processo participativo das mulheres, mediante a imposição de uma sociedade que define um lugar para o homem e outro para a mulher.

Dessa maneira, este estudo analisou algumas conexões entre o movimento feminista e a construção da categoria gênero, dando ênfase ao meio rural e a extensão rural brasileira. Inegavelmente entende-se que esse tema não se esgota nesse trabalho, mas apresenta alguns importantes elementos a respeito do assunto.

Justifica-se essa análise sobre o meio rural porque essa definição do papel do homem e da mulher ocorre de forma ainda mais acentuada nesse meio, onde o trabalho realizado pelas mulheres agricultoras, uma vez que as mesmas desenvolvem várias atividades na propriedade, são consideradas complementares ao trabalho masculino. Em virtude disso, para:

[...] as agricultoras, ao mesmo tempo que têm grande participação na produção agrícola, principalmente na de alimentos, seu trabalho tem pouca visibilidade nas estatísticas oficiais e elas formam um dos grupos mais esquecidos pelas políticas públicas (Brumer e Paulilo, 2004, p.171).

Muitas vezes o trabalho realizado pela mulher agricultora não é visto, e tão pouco reconhecido como um trabalho, sendo que o mesmo na maioria das vezes é mais considerado como afazeres domésticos, ou como um modo de ajuda. Ainda, ressalta-se que além do trabalho da mulher ser considerado complementar ao do homem, o respeito à submissão e obediência das mulheres aos homens, seja pai ou marido, existe desde quando o patriarcado era quem detinha o poder familiar.

Este viés masculino de sociedade rural pode ser considerado como um fator determinante e diferenciador da distribuição do trabalho, do rendimento, da riqueza, dos fatores produtivos e dos recursos naturais entre homens e mulheres, e que isso deve e está 
mudando a todo o momento. Nesse sentido, o movimento feminista se estruturou como um conjunto de atividades com a finalidade de buscar a igualdade política, social e econômica entre mulheres e homens.

Nesse contexto, destaca-se a importância da Extensão Rural no Brasil como uma ferramenta de fortalecimento das posições das mulheres no meio rural e na sociedade atual e julga-se necessário que a formação dos extensionistas seja feita de uma forma crítica e vivencial. Essa formação seria necessária para que se possa romper com a visão dominante que naturaliza a divisão sexual do trabalho existente e a hierarquia entre os gêneros associada a ela. Entretanto é sabido que ainda há um caminho árduo a ser percorrido por conta da história da Extensão Rural no Brasil e da maneira de fazer assistência técnica e extensão rural que ainda está imbricado nas ações e práticas do extensionistas da década de 1940.

Portanto, nota-se que existem várias razões, tanto intelectuais como políticas, para revisar a história recente de pensamento e práticas associadas com a ideia do feminismo e o debate sobre gênero. Assim, num primeiro momento fez-se uma recuperação histórica da ideia do feminismo e suas diferentes fases, e depois uma análise dos impactos disso na discussão de gênero no mundo rural e em específico na extensão rural brasileira.

\section{O CONTEXTO HISTÓRICO DO FEMINISMO}

Nem todos os que têm analisado e escrito sobre ideologias parecem à vontade com o feminismo. Essa crítica tem permeado as dimensões da criação artística, das ciências sociais, das humanidades e das ciências naturais. Alguns alegariam que ele subverte os fundamentos da cultura ocidental. Ao passo que se verifica um aumento significativo de tratados sobre o feminismo, se identifica o caráter ocasionalmente insular de algumas contribuições teóricas, que parecem ser direcionadas apenas as feministas, a mulheres que leem textos feministas ou ao público feminino em geral. E outra dificuldade da alegação essencialista acerca das mulheres, principalmente no feminismo radical, é que parece que o feminismo é discutido isolado de um contexto histórico, filosófico, político e filosófico. Sensação essa já experimentada pelas ideologias mais extremistas.

Desta forma, se analisarmos a história do feminismo como um movimento, constataremos que ele tem defendido ideias diferentes, por vezes totalmente antagônicas, partilhando, em seus valores substantivos, a mesma superposição e ambivalência da maioria das ideologias. A noção mais geral do movimento seria a de que o feminismo é buscado por 
qualquer grupo que tenha tentado mudar a posição das mulheres ou as ideias acerca destas, sendo considerado por alguns autores como um conceito amplo demais. Outros são mais precisos afirmando que a essência do feminismo consiste em favorecer que as mulheres obtenham valor igual ao dos homens, dada sua natureza comum como pessoas livres. Essa definição se aproxima da ideia de justiça sexual.

Para outros autores, o feminismo consiste em uma crítica geral dos relacionamentos sociais de dominação e subordinação sexual ou na oposição a qualquer forma de discriminação social, pessoal ou econômica em relação as mulheres por causa do sexo. Já as feministas pós-estruturalistas e pós-modernistas tem resistido a esse esforço de definição, considerando-o mais uma tentativa inconsistente de metanarrativa, ou seja, de tentar fixar e fechar num conceito. Muitas destas definições apresentadas representam facções distintas dos movimentos feministas.

Assim, as origens do pensamento feminista, segundo Vincent (1995), coincidem com os debates substantivos sobre a própria ideologia. Há uma considerável suscetibilidade em relação à questão das origens históricas do movimento. Em primeiro lugar, tem-se criticado a exclusão das mulheres ou a marginalização de sua história em virtude dos homens dominarem até pouco tempo os escritos históricos. Foram os homens que escreveram sobre as mulheres, e são naturalmente, consciente ou inconscientemente, tendenciosos, revelando uma visão masculina. Portanto, a história das mulheres precisa ser redescoberta pelas mulheres e para as mulheres.

Em segundo, essa suscetibilidade, combinada ao fato de que a disciplina da história em si pode ser parte de uma ordem masculina, patriarcal e torna as mulheres mais sensíveis em relação ao movimento. Outra dificuldade que ocorre nessa área é saber se a preocupação com as questões das mulheres implica necessariamente em uma ideologia feminista.

Face ao exposto, Vincent (1995) refere que o debate concernente às origens do pensamento e das práticas feministas pode ser dividido em quatro categorias, sendo que a primeira confirma que o feminismo data dos primórdios da consciência humana e que a questão da mulher sempre existiu. O espírito feminino é único, imutável e inteiramente diferente do masculino. A segunda situa-se no século $\mathrm{XV}$, em Christina de Pisan, que escreveu o Livro das cidades das senhoras (1405).

A terceira referente à Aphra Behn (1640-1680), cuja vida, relativamente curta, abrangeu diversas experiências. Esteve envolvida na rebelião nas Índias ocidentais, tendo escrito 17 peças e 30 romances. Parece que promoveu ativamente a ideia de igualdade para as mulheres. 
E por fim, a quarta categoria, data do fim do século XVIII, principalmente posterior a Revolução Francesa. O feminismo ocidental tem aí a sua origem, embora algumas correntes o antecedam à revolução (VICENT, 1995).

Em relação à literatura sobre o feminismo, identifica-se que esta tem expandido consideravelmente, principalmente a partir da década de 1960, revelando junto com o ecologismo, temas frequentemente citados. Partindo desta análise, em que a produção de textos, a agitação e a consciência política feminista se disseminaram, é possível identificar diversas subdivisões, sendo que a mais convencional, na percepção de Vincent (1995), se dá entre dois movimentos: o primeiro compreende o período de 1830 a 1920 (primeira onda) e o segundo de 1960 em diante (segunda onda). Afirma-se que de 1920 a 1960 foi um período de estagnação. Nem todas as feministas seguem essa classificação. Para algumas, o segundo movimento foi subdividido em duas e até cinco fases. Outras referem que o feminismo pósmodernista que significa um terceiro movimento.

A primeira onda do feminismo tem como pano de fundo a perspectiva liberal clássica dos direitos e a propagação da linguagem lockiana no começo do século XIX. Neste sentido, Narvaz e Koller (2006), referem que a primeira geração ou primeira onda representa o surgimento do movimento feminista, que nasceu como movimento liberal de luta das mulheres pela igualdade de direitos civis, políticos e educativo; direitos estes que eram reservados apenas aos homens.

O envolvimento das mulheres em movimentos antiescravistas e sufragistas do século XIX, e que se estruturaram na Inglaterra, França, Estados Unidos e Espanha, teve fundamental importância nessa fase de surgimento do feminismo. O objetivo principal deste período era a luta contra a discriminação das mulheres e pela garantia de direitos, inclusive do direito ao voto, bem como a denúncia da opressão à mulher imposta pelo patriarcado (NARVAZ e KOLLER, 2006).

Desta forma, a consolidação do capitalismo e a nascente industrialização, de acordo com Gurgel (2010), provocaram um conjunto de alterações de ordem econômica, social e política que tiveram grandes repercussões na vida das mulheres, que seguiam excluídas dos direitos civis, políticos e educativos. Assim, a luta sufragista emerge neste contexto, pois as mulheres defendiam que o sufrágio universal possibilitaria o acesso das mulheres ao parlamento e, por conseguinte abriria a possibilidade de mudança no conjunto das leis e instituições. A luta sufragista também possibilitaria uma ampla aliança entre mulheres, unificando posições políticas diferentes. 
Este feminismo inicial, tanto na Europa, Estados Unidos como no Brasil, perdeu força a partir da década de 1920, após a conquista do voto pelas mulheres, e só aparecerá novamente, com importância, na década de 1960. Muitas autoras preocupadas com o feminismo entraram em um período de calmaria e se limitaram a participar de algumas campanhas pacifistas. A Grande Depressão e os períodos de guerra absorveram grande parte da energia e atenção das mulheres. As questões pelas quais se lutava nessa época eram práticas e imediatas, relativas às preocupações com o bem estar e a preservação da unidade familiar (VINCENT, 1995; PINTO, 2010).

A segunda onda feminista teve seu início identificado nos anos 1960. Em virtude do grande desenvolvimento da educação das mulheres, a partir dos anos 1940, por toda Europa e Estados Unidos; estas se qualificaram e passaram a assumir diversas profissões que anteriormente eram exercidas por homens. Medidas como a legislação do aborto, igualdade de salário e de direitos civis, controle da natalidade, pílula anticoncepcional facilitaram a maior liberdade de escolhas das mulheres, tanto na esfera pública quanto privada. O feminismo aparece como um movimento libertário, que não quer só espaço para a mulher - no trabalho, na vida pública, na educação -, mas que luta, sim, por uma nova forma de relacionamento entre homens e mulheres, em que esta última tenha liberdade e autonomia para decidir sobre sua vida e seu corpo (VINCENT, 1995; PINTO, 2010; NARVAZ e KOLLER, 2006).

Durante este período, a literatura sobre o feminismo começou a crescer significativamente. Os livros "O segundo sexo", de Simone de Beauvoir, publicado pela primeira vez em 1952 e "A mística feminina", de Betty Friedan, publicado em 1965, marcaram essa nova onda do feminismo. E o termo feminismo foi popularizado na GrãBretanha pelas obras de Germaine Greer e Juliet Mitchell. Assim, no decorrer é possível perceber várias mudanças de atitudes sociais das mulheres em relação ao casamento, divórcio e trabalho. Gradativamente as mulheres assumem sua independência, do ponto de vista financeiro, social e moral, de instituições como a família. Nos Estados Unidos se verifica uma verdadeira explosão de grupos feministas no fim dos anos 1960 e começo dos 1970.

Neste contexto, as longas manifestações feministas ocorridas neste período foram acompanhadas de fortes questionamentos ao poder do Estado, da família e da Igreja, considerados pontos de sustentação ideológica do capitalismo em todos os seus mecanismos de dominação e opressão da vida social. Ao mesmo tempo, os partidos de esquerda resistiam a encampar estas bandeiras e muitas vezes as mulheres eram ridicularizadas em suas manifestações no interior destas organizações (GURGEL, 2010). 
Vincent (1995) refere que nos anos 1970, muitas das mulheres que haviam participado nas campanhas dos direitos civis, anti-Vietnã e nos movimentos pacifistas de 1960, começaram a se interessar pelas questões feministas, em virtude do desencantamento com o sexismo dos grupos socialistas marxistas, levando suas crenças marxistas e libertárias radicais para o feminismo. Os anos 1980 também evidenciaram fortes críticas na Europa e Estados Unidos, da Nova Direita sobre a legislação do aborto e direitos civis e a confirmação da importância da família tradicional patriarcal, além da tensão constante relacionada ao Estado de Bem Estar Social, afetando diretamente as mulheres.

A partir dos anos 1980, a crítica pós-modernista da ciência ocidental introduz o paradigma da incerteza no campo do conhecimento. As feministas francesas, influenciadas pelo pensamento pós-estruturalista que predominava na França, especialmente pelos pensamentos de Foucault e Derrida, passam a enfatizar a questão da diferença, subjetividade e da singularidade das experiências, concebendo que as subjetividades são construídas pelos discursos, em um campo que é sempre dialógico e intersubjetivo. Alguns autores consideram esse momento como a terceira onda do feminismo. Com isso, desloca-se o campo do estudo sobre as mulheres e sobre os sexos para o estudo das relações de gênero (NORVAZ E KOLLER, 2006).

As três gerações do feminismo, quer em seus aspectos políticos quer nos teóricoepistemológicos, não podem ser entendidas desde uma perspectiva histórica linear. As diferentes propostas características de cada uma destas fases do feminismo sempre coexistiram, e ainda coexistem, na contemporaneidade. A fase surgida mais recentemente, a terceira geração do feminismo, tem grande influência sobre os estudos de gênero contemporâneos.

Considerando a perspectiva histórica, de uma maneira geral, o feminismo fragmentou-se em várias escolas diferentes que refletem ênfases e doutrinas distintas, e que causa para algumas feministas certos descontentamentos. As principais escolas do feminismo adquiriram uma espécie de status ortodoxo, sendo as mais citadas o feminismo liberal, o feminismo socialista marxista e o feminismo radical.

Além destas, Vincent (1995) nos chama a atenção para incluirmos também as pósmodernistas, que são as mais recentes e para reconhecermos outras que se encontram na periferia do movimento, como as feministas negras, feministas anarquistas e o eco-feminismo. Por último, ressalta que devemos considerar as controvérsias relacionadas ao pensamento maternal e a ética do cuidado, bem como o contraste existente, por parte de algumas 
feministas sobre o feminismo cívico e o feminismo maternal. Alguns aspectos do feminismo maternal foram intitulados de feminismo conservador pró-família.

Em relação ao feminismo liberal, este emerge dos ideais políticos liberais de igualdade, liberdade e fraternidade, surgidos nos séculos XVII e XVIII, sendo que o objetivo principal era a busca por igualdade. Por outro lado, o feminismo liberal encontrava-se em um contexto em que as mulheres não exerciam o direito ao voto, não podiam ser proprietárias, e nos ambientes organizacionais, quando inseridas, só ocupavam posições subalternas, sendo cada vez mais isoladas e dependentes dos homens. O feminismo liberal antecipa um futuro de completa justiça sexual.

Apesar da literatura, às vezes, dividir feminismo socialista e feminismo marxista, o marxismo é considerado por Vincent (1995) como uma espécie do gênero do socialismo. O marxismo não é a síntese ou realização do socialismo. Nesta abordagem a construção do gênero é um processo social não só entre sexo, mas também, ideológico, racial e de opressão dos sistemas capitalista e patriarcal. A maioria das interpretações socialistas ortodoxas do papel da mulher, de 1920 ao final dos anos 1950, assumiu formato utópico ou da antiga posição de Marx e Engels. O final dos anos 1960 e o início dos 1970 testemunharam uma rejeição limitada dessa antiga estrutura, sobretudo a de Engels, e a tentativa de criar um novo feminismo socialista.

O feminismo radical iniciou no final dos anos 1960 e início dos 1970, fruto da insatisfação das feministas com a subordinação da mulher ao homem, e a dominação amplamente apoiada pelas políticas de direita desse período. É também conhecida como segunda onda do feminismo. Beauvoir defendeu o livre controle da natalidade, o aborto e menos relevância a monogamia para facilitar a inserção das mulheres no mundo cultural com os homens. Esta abordagem traz em si duas limitações: a utopia de pretender a separação total entre homens e mulheres e a crença na possibilidade da construção de organizações alternativas ao sistema capitalista.

E no fim dos anos 1980, aumenta o interesse feminista pela teoria pós-estruturalista e pelo pós-modernismo, inicialmente nas áreas da crítica literária e cultural. O feminismo pósestruturalista e pós-moderno concentra-se no paradigma da linguagem. Sua preocupação primordial é desconstruir a linguagem e os textos existentes. A linguagem é percebida como uma arma potente para tornar ineficaz e expor o patriarcado no campo da cultura e da literatura. 
Portanto, enquanto na Europa e nos Estados Unidos o cenário era muito propício para o surgimento de movimentos libertários, principalmente aqueles que lutavam por causas identitárias, no Brasil e na América Latina, os movimentos de mulheres desempenhavam, na década de 1980, um papel importante no processo de democratização da América Latina, que vivia em profundas desigualdades sociais decorrentes do desenvolvimento da industrialização, urbanização e modernização dos países. Sua contribuição se deu tanto na luta contra os regimes militares, quanto no esforço de se institucionalizar, no âmbito do próprio estado, uma agenda política a serviço das demandas de mulheres. Fica claro que as mulheres dos países pobres ou periféricos são as principais perdedoras, resultado da justaposição de sua posição subordinada no sistema econômico mundial e de sua condição de mulher, no contexto das relações patriarcais (GURGEL, 2010; NARVAZ e KOLLER, 2006, PINTO, 2010).

Essas lutas representaram ganhos em termos de construções de políticas voltados as questões das mulheres no decorrer dos governos pós-ditadura. A emergência das mulheres rurais, por exemplo, nos movimentos sociais neste período proporcionou seu aparecimento como sujeito político, rompendo sua invisibilidade como trabalhadora. Assiste-se a um aumento significativo de movimentos de mulheres (negras, universitárias, católicas, lésbicas, etc.) debatendo temas que tratam da relação das mulheres com o desenvolvimento e os efeitos deste sobre as mulheres, visando assinalar os impactos negativos das políticas econômicas aplicadas principalmente nos países periféricos, frutos da globalização.

\section{QUESTÕES DE GÊNERO NO MEIO RURAL BRASILEIRO}

A dimensão de gênero ainda é uma dimensão da desigualdade social no território rural, cujo reconhecimento se expressa na constatação de uma hierarquia no ser, ter e estar entre homens e mulheres, com reconhecimento da desvalorização, exploração, opressão e subordinação das últimas (BUARQUE, 2015).

Ressalta-se que muitas vezes o trabalho realizado pela mulher agricultora não é visto, e tão pouco reconhecido como um trabalho, sendo que o mesmo na maioria das vezes é mais considerado como afazeres domésticos, ou como um modo de ajuda.

Diversos estudos que examinaram a divisão do trabalho por sexo na agricultura permitem concluir que as mulheres (e, de um modo geral, também as crianças e os jovens) ocupam uma posição subordinada e seu trabalho geralmente aparece como 'ajuda', mesmo quando elas trabalham tanto quanto os homens ou executam as mesmas atividades que eles. (BRUMER; PAULILO, 2004, p. 210, grifo nosso) 
Outras vezes, os trabalhos realizados pelas mulheres, são determinados pela condição física, sendo que os trabalhos domésticos, para muitos são considerados leves, e destinados na grande maioria, às mulheres e filhas, enquanto os homens cuidavam das lavouras e da agricultura. Mas há controvérsias quanto a essas condições, pois conforme Brumer e Paulilo (2004, p. 211) "[...] a mulher executa tanto trabalhos leves como trabalhos pesados como trabalhar na colheita dos produtos agrícolas, carregar os filhos e buscar água em lugares distantes do domicílio". É válido ressaltar que a divisão das atividades de trabalho na propriedade, na maior parte das vezes, são determinadas pelo homem ao qual cabe estabelecer a cada membro da família, as suas funções na propriedade.

O que se nota, é que a mulher tem um papel fundamental, seja na família, propriedade, comunidade ou na sociedade em geral. A mulher ao longo do tempo vem conseguindo abrir muitas barreiras e tem avançado nas discussões sobre igualdade de gênero. Mas, o maior impedimento é de vivermos em uma sociedade em que culturalmente as relações de poder são patriarcais, as quais atribuem ao homem a responsabilidade de provedor, tornando-o também o responsável pelas decisões a serem tomadas, sendo que a mulher acaba ficando em segundo plano, e em muitas vezes nem são consultadas sobre determinadas decisões e escolhas (FORLIN,2014).

Conforme Buarque (2015) o reconhecimento de que o gênero se constitui numa dimensão da desigualdade social no mundo rural brasileiro não elimina, contudo, as divergências sobre como tratá-la teórica e praticamente. Três grandes ambientes trazem as indicações da desigualdade: o das análises apoiadas na teoria feminista da democracia de gênero e de conteúdo político que se pode emancipar; o de outras perspectivas teóricas, no qual predominam a análise e saída economicistas para a desigualdade, sem questionamento da dominação masculina; e o do senso comum, onde imperam duas visões que se complementam: a essencialista e a tradicionalista, também de forte comprometimento religioso, que reconhece, consciente ou inconscientemente, na perspectiva patriarcal, a única fonte de inspiração para a organização familiar, buscando no discurso sobre a preservação da cultura camponesa argumentos que justifiquem uma inanição política por parte das mulheres.

Esses três ambientes constituem o território das relações de gênero, no qual os agentes sociais se articulam e competem na busca da posição de sujeito do processo de emancipação das mulheres rurais. Esse processo iniciou na década de 1980, com o surgimento do movimento social das mulheres, no espaço rural, o Movimento de Mulheres Trabalhadoras 
Rurais, simultaneamente ao Movimento dos Sem-Terra, e também a criação das políticas de identidade.

Contudo, a movimentação existente indica, positivamente, o crescimento da importância das questões de gênero no âmbito rural. Principalmente quanto ao fato de as trabalhadoras mobilizarem-se para tomar as decisões sobre as próprias vidas, contrapondo-se aos fatos ocorridos no âmbito da construção patriarcal. Historicamente a direção de seus destinos é ou era decidida a partir da tradição, da natureza e das perspectivas técnicas, teóricas e políticas que não reconhecem a dominação masculina e a opressão de gênero como questões relacionadas à democracia, ao desenvolvimento e à felicidade da sociedade. Neste momento, a discussão retorna para uma das mais importantes questões de gênero ligadas ao mundo rural contemporâneo e ao patriarcado, que é a posição da agricultura familiar e a reprodução social (BUARQUE, 2005).

Ainda conforme o mesmo autor foram às dificuldades de sobrevivência aliadas ao tempo maior das mulheres fora da agricultura patronal que gerou a agricultura familiar como uma estratégia de sobrevivência, e que vai ocupar, basicamente, a força de trabalho feminina e das crianças. São as agricultoras, por essa condição, que vão preservar as habilidades necessárias aos diferentes tipos de cultivos e criação de diversas espécies de animais de pequeno porte, bem como o manejo do gado leiteiro, no espaço da agricultura familiar.

Nesse sentido, são elas que vão produzir alguns artesanatos e beneficiar produtos advindos dos roçados e quintais em torno de suas casas. Por esse caminho, pode-se registrar que foram as mulheres que mais contribuíram para a preservação da biodiversidade no pequeno lote de terra, por meio da seleção de espécies de sementes, preservando a cultura dos quintais e a criação de pequenos animais. Entretanto, Brumer e Anjos (2008) numa análise sobre gênero e reprodução social na agricultura familiar, afirmam que mesmo com avanços em algumas políticas, ressalta-se sobre a necessidade de investigações sobre como a masculinização e o êxodo de mulheres jovens do meio rural e da agricultura podem estar ligados a estratégias familiares de reprodução social, nas quais se articulam sucessão na propriedade familiar, formação educacional e profissional dos filhos e filhas e migração destes para outras regiões rurais ou urbanas.

As questões relativas à manutenção da exclusão feminina da sucessão na propriedade familiar também são particularmente pertinentes. É preciso analisar como a valorização da escolarização e o acesso a profissões não agrícolas acentuam a tendência à exclusão feminina da atividade agrícola. Ao mesmo tempo, formas de questionamentos desta exclusão por 
mulheres agricultoras são ainda pouco visíveis, abrindo uma agenda de pesquisa sobre suas modalidades de existência e seus significados.

Desse modo, as mulheres nem foram reconhecidas, no passado, como trabalhadoras, pelo fato de realizarem as tarefas produtivas no espaço da agricultura familiar e correm grandes riscos de não serem no presente, quando se redefinem valores para esse sistema de produção e se nomeiam novamente os seus produtos. Dentro dessa mesma lógica, o trabalho doméstico propriamente dito é desprovido de qualquer relevância social ou econômica, carregando todo o estrato da população do campo que a ele se dedica, no caso, as mulheres, ha uma situação de desvalorização de forte impacto sobre a sua autoestima.

Por fim, Buarque (2005) afirma que mesmo com todo o esforço de criação e de implementação de políticas públicas compensatórias que atualmente estão sendo aplicadas no espaço rural, as mulheres, que garantem a sobrecarga da agricultura familiar, são menos remuneradas, têm menos conforto, menos chances de diversão e sofrem mais restrições à participação na vida política.

\section{GÊNERO E EXTENSÃO RURAL BRASILEIRA}

Apesar de todo avanço no mundo do movimento feminista, no Brasil, caminhou a passos lentos, especialmente no meio rural e na Extensão Rural. De maneira geral, iniciada em 1948, a Extensão Rural no Brasil tem um passado balizado pela perspectiva de desenvolvimento exógeno e por práticas difusionistas vinda da teoria desenvolvimentista e do processo de modernização da agricultura. Percebe-se assim, a inquietação, entre as décadas de 1940 e 1960, em instituir o mundo social dos agricultores via percepções distintas de trabalho (lavoura para homens e trabalho doméstico feminino).

Após esse contexto, surge a política de formação de agricultores norteada por fundamentos de desigualdades sociais, os quais frisavam diferenças de papéis e relações entre agricultores (as), extensionistas rural e doméstica. Contudo, a partir de 1980, com o direcionamento político destinado ao desenvolvimento local, passa-se a priorizar a participação dos sujeitos na formulação e destinação de políticas públicas. Ou seja, somente a partir dos anos 1980, que as ações das mulheres começaram a ser reconhecidas por meio de conquistas e obtenções de direitos.

Estabelecendo mais detalhes, os extensionistas de décadas atrás, tinham consigo valores e visões de mundo marcadas pela ideia do difusionismo e da transmissão unilateral de conhecimentos, tendo como papel tecnicista de "agente de desenvolvimento", apoiado pelo 
modelo de modernização da agricultura. Nessa época, a forma de tratar homens e mulheres, carrega-se de uma tradição de trabalho no campo em que há uma segmentação definida, baseada na aceitação da divisão de gênero do trabalho dominante, que se transformam em objetivos, métodos de trabalho e público diferenciados para as instituições de extensão.

Segundo Siliprandi (2000), tivemos durante décadas (e em muitos casos, temos ainda) na extensão rural, a separação entre a chamada área econômica ou técnica do mundo da produção, da agricultura comercial, da venda dos produtos, das tecnologias modernas, exercido geralmente por homens agrônomos, técnicos agrícolas, veterinários, etc. e voltada para os agricultores homens. Já a área chamada social, que inclui os temas ligados ao lar, como a alimentação, a saúde, a educação básica, o relacionamento familiar, o saneamento, e atividades consideradas femininas (artesanato), exercidas geralmente por mulheres assistentes sociais, professoras, nutricionistas, etc., dirigida às mulheres rurais.

Embora esse modelo de extensão difusionista e de transmissão unilateral de conhecimentos tenha-se modificado nos últimos anos, principalmente em razão da pressão que os movimentos sociais exerceram no Estado, observa-se que muito dessas ideias permanecem nas cabeças daqueles que trabalham no campo. Contudo, as principais transformações que se verificaram foram: a preocupação para que os grupos de mulheres se transformassem em grupos produtivos (na busca de uma complementação da renda familiar), e a introdução da problemática acerca do reconhecimento das mulheres rurais como trabalhadoras, para fins da previdência social. Segundo Siliprandi (2000) e Farah (2004), no campo da participação política e em fóruns de decisão locais e regionais, privilegiou-se o estímulo à participação das mulheres agricultoras nos Conselhos de Saúde e de Educação.

Nesse sentido, é valido destacar que uma das medidas de reconhecimento das mulheres no campo foi à discussão que se iniciou nos últimos anos sobre o tema Relações de Gênero na Agricultura Familiar. Esse tema tem como objetivo chamar a atenção para a necessidade de participação das mulheres agricultoras nos processos de discussão que estavam sendo propostos, assim como rediscutir a forma de enfocar os trabalhos da extensão voltados para homens e mulheres.

Segundo Siliprandi (2000) e Farah (2004), esta discussão teve uma boa aceitação entre o conjunto de técnicos extensionistas, mas observou-se uma série de resistências para eximirse da responsabilidade de buscar respostas a estas questões como: técnicos despreparados para enfrentar novas situações ou não tinham disposição para enfrenta-las; técnicos que afirmavam ter receio de serem mal interpretados pelos maridos por estarem se dirigindo às suas esposas 
ou filhas; enfrentavam problemas de faltas das participantes às atividades coletivas, em função da sobrecarga com o trabalho doméstico ou por causa de problemas familiares.

Para as profissionais mulheres que trabalham na extensão, também não é fácil adaptarse a uma nova situação. As extensionistas enfrentam o problema de serem vistas como profissionais inferiores por parte do público agricultor e por seus colegas (quando não pelas próprias instituições), já que o trabalho com mulheres é um trabalho desvalorizado e muitas vezes diminuindo sua importância. Além de que as pressões que recebem num outro momento são para que passem a realizar projetos de geração de renda, como se de repente fosse possível transformar a maioria das agroindústrias domésticas em fonte de renda e ocupação para as mulheres e jovens das comunidades rurais.

Do ponto de vista institucional, adentrar nas questões de gênero sugere novos planejamentos e critérios de monitoramento e avaliação, sendo que apesar de já se ter avançado significativamente na elaboração de metodologias que ajudam a enfocar as questões de gênero no nível institucional, este é um tema novo para as organizações. Com isso, a Extensão Rural requer esforços e investimento em capacitação e na adequação de metodologias de trabalho, o que nem sempre está colocado como prioridade para essas instituições (SILIPRANDI,2000).

São muitos os caminhos que podem ser trilhados, na busca do fortalecimento das posições das mulheres no conjunto da sociedade, mas observa-se que do ponto de vista da Extensão Rural no Brasil, ainda que é necessário que a formação dos extensionistas seja feita de uma forma crítica e vivencial. Assim, para alguns avanços é necessário romper com a visão dominante que naturaliza a divisão sexual do trabalho existente, e a hierarquia entre os gêneros associada a ela.

\section{CONSIDERAÇÕES FINAIS}

Certamente, o feminismo está longe de ser um consenso na sociedade como um todo, inclusive na brasileira, considerando a implantação de políticas especiais para mulheres que ainda enfrentam muitas resistências culturais e políticas. Por tudo isso, destaca-se a necessidade dos movimentos de mulheres se fortalecerem e se reafirmarem como movimento, construindo diversos espaços amplos de articulação e lutas políticas que consigam reconhecer e aliar as múltiplas dimensões que compõem as experiências das mulheres, tais como classe, raça, geração, sexualidade, afetividade, entre outras. 
Observa-se que apesar de todo avanço no mundo do movimento feminista, no Brasil essa discussão caminhou a passos lentos, especialmente no meio rural e na Extensão Rural. Apesar de todo esmero atual de criação e de implementação de políticas públicas compensatórias, as mulheres agricultoras são menos remuneradas, têm menos conforto, e sofrem mais restrições à participação na vida política.

$\mathrm{Na}$ Extensão Rural, apesar de se ter modificado nos últimos anos, nota-se que muito das ideias da época difusionista permanecem ativas no campo, contudo, com algumas transformações como: a preocupação para que os grupos de mulheres se transformassem em grupos produtivos e a introdução da problemática acerca do reconhecimento das mulheres rurais como trabalhadoras, para fins da previdência social. Do ponto de vista institucional da Extensão rural, questões de gênero sugerem novos planejamentos e critérios de monitoramento e avaliação, ou seja, este é um tema novo para as organizações e requerem esforços e investimento em capacitação e na adequação de metodologias de trabalho para os extensionistas.

Portanto, destaca-se que são muitos os caminhos que podem ser trilhados, na busca do fortalecimento das posições das mulheres no conjunto da sociedade, ressaltando que para entender as discussões de gênero no meio rural é necessário lembrarmos que a luta do feminismo em torno das relações de gênero são construídas socialmente, e com isso, se tem modificações ao longo do tempo. Contudo, o que nos permite afirmar é que a história do feminismo está começando a ser construída socialmente e analisada por mulheres, assim como o ideário feminista nos conduz.

\section{REFERÊNCIAS BIBLIOGRÁFICAS}

ABRAMOVAY, R. (2001). Conselhos além dos limites. Texto preparado para o Seminário Desenvolvimento Local e Conselhos Municipais de Desenvolvimento Rural, organizado pelo EMATER/RS. FETAG/RS com apoio da GTZ - nos dias 20 e 21 de junho de 2001.

BRUMER, A.; ANJOS, G. Gênero e reprodução social na agricultura familiar. REVISTA NERA - ANO 11, N. 12 - JANEIRO/JUNHO DE 2008.

BRUMER, A.; PAULILO, M. I. As agriculturas do sul do Brasil. Revista Estudos Feministas. vol. 12. n. 01. Florianópolis. Jan./Apr. 2004. Disponível em: http://www.scielo.br/pdf/ref/v12n1/21697.pdf . Acesso em 24 de set. 2015. BUARQUE, C. A dimensão de gênero no mundo rural brasileiro contemporâneo. In. Miranda, C., Costa, C.(Orgs.). Desenvolvimento Sustentável e Perspectiva de Gênero. Brasília: IICA, 2005. 
FARAH, M. F. S. Gênero e políticas públicas. Revista Estudos Feministas, Florianópolis, 12(1): 360, janeiro-abril/2004.

FORLIN, V.; MIRALES R. Relações de Gênero e Geracionais na Agricultura Familiar. $6^{\circ}$ Seminario Nacional Estado e Politicas Sociais. Toledo-PR, 2014.

GURGEL, Telma. Feminismo e Luta de Classe: história, movimento e desafios teóricopolíticos do feminismo na contemporaneidade. Seminário Internacional Fazendo Gênero 9 (2010): 1-9.

NARVAZ, Martha Giudice; KOLLER, Sílvia Helena. Metodologias feministas e estudos de gênero: articulando pesquisa, clínica e política. Psicologia em Estudo 11.3 (2006): 647654.

PINTO, Céli Regina Jardim. Feminismo, história e poder. Revista Sociologia Política. 18 (36), Curitiba, jun. 2010, pp.15-23.

PNUD. (2015). Disponível em http://www.pnud.org.br/odm.aspx acessado em 27.09.2015.

SILIPRANDI, E. Mulheres rurais e políticas de desenvolvimento: considerações a partir da extensão rural. EMATER. Rio Grande do Sul. Brasil. 2000.

VINCENT, A. (1995). Ideologias políticas modernas. Rio de Janeiro: Zahar. (Capítulo 7: Feminismo). 